\title{
Agriculture Technology as a Tool to Influence Youth Farming in Ghana
}

\author{
Benjamin Danso Kwakye1, Robert Brenya ${ }^{2 *}$, Derrick Acquanah Cudjoe ${ }^{3}$, \\ Agyemang Kwasi Sampene ${ }^{4,5}$, Fredrick Oteng Agyeman ${ }^{4,5}$
}

\author{
${ }^{1}$ School of Management, University of Science and Technology of China, Hefei, China \\ ${ }^{2}$ College of Economics and Management, Nanjing Agricultural University, Nanjing, China \\ ${ }^{3}$ School of Economics and Management, Southeast University, Nanjing, China \\ ${ }^{4}$ Department of Management Sciences \& Engineering, Jiangsu University, Zhenjiang, China \\ ${ }^{5}$ School of Management, Jiangsu University, Zhenjiang, China \\ Email: ^brenyarobert@yahoo.com
}

How to cite this paper: Kwakye, B.D. Brenya, R., Cudjoe, D.A., Sampene, A.K. and Agyeman, F.O. (2021) Agriculture Technology as a Tool to Influence Youth Farming in Ghana. Open Journal of Applied Sciences, 11, 885-898.

https://doi.org/10.4236/ojapps.2021.118065

Received: July 17, 2021

Accepted: August 16, 2021

Published: August 19, 2021

Copyright (c) 2021 by author(s) and Scientific Research Publishing Inc. This work is licensed under the Creative Commons Attribution International License (CC BY 4.0).

http://creativecommons.org/licenses/by/4.0/

\section{Open Access}

\begin{abstract}
The extent of engagement of the youth going into farming is steadily seen as the modern-day panacea for sustainability and extenuation of food insecurity. Yet, this plodding-shift of the youth has opened new doors for a different problem that needs efficient agricultural resolution. The study examines the correlation between youth farming and the various factors that influence the youth to go into agriculture using data obtained from the Ghanaian youth. We applied Explanatory Factor Analysis (EFA) of the paradigms, with principal component factoring. The results justified using Confirmatory Factor Analysis (CFA) in AMOS and R. The results showed that technology outperforms factors such as motivation, economics, and government policies to significantly influence the youth towards farming. Attitude and knowledge were also found to have an indirect influence on youth farming. The paper contributes to the theoretical influence of technology on the youth and on the practicality of agricultural farming.
\end{abstract}

\section{Keywords}

Agriculture, Explanatory Factor Analysis, Structural Equation Modeling, Technology, Youth Farming

\section{Introduction}

Technology is gaining eminence in the agricultural industries [1]. According to Lin and Huang [2], users will accept technology that performs the user's preferred task, vice versa. And this willingness to accept has revolutionized modern 
agricultural technology to increase the production of quality and quantity agricultural products whiles reducing loss and labor [3]. The world population comes with its predicaments in food insecurity issues, agricultural goods and services fluctuation, price escalation, hunger, poverty, and the like [4]. Agricultural technology stands to be the only solution to curb this canker [5].

Tang et al. [6] added that technology would take a significant role in agriculture in the coming decades, and farmers will become more informed and productive via smart farming with automated operations. Currently, in Ghana, every farmer in the country uses mobile connectivity in agricultural activities; in the research conducted by Verduyn et al. [7] indicated that billion people used smartphones, and it is estimated to go high in the mid-century. Some governments bring technology innovations into the farming industry to train the farmers about the use of farming equipment and machinery, electronic devices, and the like for them to be at par with the dynamic nature of agriculture farming [8].

Consequently, technology application has been a milestone in Ghana, especially in the Northern Region, where there are low per capita income and uppermost poverty rates [9]. Farmers can use Information and Communication Technology (ICT) devices to relay information to the agricultural stakeholders who significantly influence the production of the farm crops [1]. The study asks this question; what factors influence the youth to go into farming? This examines the factors that might affect the youth to adopt agricultural technology in Ghana, the challenges, and opportunities. Likewise, not only will this study helps fill the literature gap, but also gives a graphical assessment of other factors that influence the other toward youth farming.

The rest of the paper proceeds as follows; previous works relating to agricultural technology, followed by the systematic approach of the research model and its interpretation. Next, the paper focused on the results and discussion of discoveries during the investigation. The last part is the conclusion of the study.

\section{Related Works}

At present agriculture farming activities entail information accuracy, forecast, proficiency in farming operations [10] to sustain food production [4]. This has been the consistent activity that supplies food in developing countries [11]. Damba et al., [9] asserted that farming output mitigates the uncertainty in food production, livelihood, and poverty among the emerging economies. Technology has been a reliable instrument with diversified strategies that provide mass agriculture produce in developed nations. In the past decades, technology has changed breeding domestic animals and crop cultivation [12]. The application of technology for agricultural growth is an unavoidable issue facing today's farmers [13]. Farmers now use technological tools and other appliances to improve cultivations [11] in the farmlands. Damba et al. [9] added technology in this century plays an essential role in agricultural production, especially in the area of smart farming [14], drone applications [15], decision making, sustainability, and productivity of food, [16]. Porter and Heppelmann [17], defines technology as 
the use of machinery and scientific knowledge to reduce intensive labor whiles increasing agricultural production. Walter et al. [18], added these types of machinery mitigates workloads, minimizes the footprint of farming, and enhances resource integrations.

Furthermore, weedicides and fertilizers have taken the place of the weeding and manure application practices among farmers in developing countries [19]. Likewise, precision farming [4], has enabled accurate soil moisture measurement [12], and swift planting of seedlings on the farmlands [6]. Furthermore, technology application such sensors usage such as $\mathrm{CO}_{2}$ concentration sensor, humidity sensor, etc., in the agrarian field nursing structure prevent excess materials such as water [14]. This has made huge impacts on the variations of fertilizer, workforce, fallow period, etc. [20]. Amankwah [21], asserted, technology utilization in the farming system has boosted biogas integration through raw materials such as agricultural waste, plant materials, food waste, manure, and the like. Farmers can also walk in the farm areas while tracking the farmland with Global Positioning System (GPS) device to capture the total area [19].

In 2005, the World Economic Forum announced 500 million peripheral devices are linked to the Internet, 8 billion are connected presently, and it is predicted to be 1 trillion in 2030 [22]. These technological devices have facilitated agriculture and the art of agriculture with a prediction of yield, enabling farmers to take appropriate storage measures [14]. Furthermore, agriculture technology is on its way to revolutionize [23] the farming industry, and farmers must prepare themselves to embrace the new future [8].

According to Verspagen [24], technology is of no use to agriculture economic development if it is unknown to the people. The knowledge of the technology used must be properly circulated [25] to influence farmers in its operation. Channels such as the extension officers [26], Community farm associations, Farmer-to-Farmer interactions [27], agriculture institutions in the country, etc., must be operational in the dissemination of technical information.

Conley et al. [28] stated new users might also learn the technological features from others while other factors such as education, farm size, etc. also play an essential role in technology enactment [25]. Also, the outline of agricultural policies and provisions made for a particular technology defines its acceptance [5]. Moreover, many perceive technology usage as a decree to their freedom [29], while others refrain from it due to cultural or religious beliefs. Yet, the millennial farmers feel easy in this virtual agricultural environment [8], while long-standing farmers can accept technological innovations if productivity increases whereas labor reduce [30].

Technology inclusion in the agriculture industry is a milestone in affirming food security, [31]. In the research conducted by Kansanga et al. [19] on "Traditional agriculture in transition: examining the impacts of agricultural modernization on smallholder farming in Ghana under the new Green Revolution," the study confirmed the significance of using technology to enhance modern-day agriculture productivities. 


\section{Methodology}

With careful consideration of identifying technology as a tool to influence youth into farming, the researchers designed a questionnaire containing demography questions and the remaining items grouped into 5 constructs measuring the factors outlined in research hypotheses. The research questionnaire was subjected to scrutiny by researchers who have expertise in the field. This implies that the face validity of the questions was justified. Nevertheless, the content validity was measured using the Content Validity Ratio (CVR) for each index. The threshold of CVR for considering the content validity as satisfactory at a $95 \%$ confidence level is 0.75 [32]. The reliability of the research questionnaire was tested using Cronbach's Alpha. The test result reveals that the research questionnaire is reliable to be used as a measuring tool for the research, given that the Cronbach's Alpha is at least 0.7.

In Table 1, the scales depict an acceptable Cronbach's Alpha $>0.7$, showing good reliability. To establish convergent validity, each factor was measure at the threshold of 0.6 following input from [33] for research of this nature [34]. Comrey and Lee (1992) back our guide for selecting the sample size of just over three hundred participants in [35] who gives the scales as follows: $100=$ Poor; $200=$ Fair; $300=$ Good; $500=$ Very Good; 1000 or more $=$ Excellent. Partici pants comprised a sample of $70 \%$ males and $30 \%$ females. Our sample participants are youth from Ghana who willingly responded to the questionnaires with an age range from 18 to 34 years old and educated with at least a High School Diploma. The majority of them have either a Bachelor's degree $(36.5 \%)$ or a Master's degree (38\%), with a handful of them holding a Ph.D. (9.4\%). The data collected was assessed for missing values and outliers using RStudio; no missing data was found, and no outliers meaning normality assumption, are assured. Below in Table 2 is the display of the mean and standard deviation of the measure items for each of the constructs in the questionnaire where $\mathrm{N}$ is the number of respondents for that particular item (in this case, the same number of responses for each item).

The data analysis for this paper was generated using RStudio Statistical Software, SPSS (and AMOS), and the Real Statistics Resource Pack software (XRealStats v 7.6). The IBM Statistics Package for Social Science (SPSS v 24) was used to conduct the Explanatory Factor Analysis (EFA) of the constructs, with principal axis factoring. The results justified using Confirmatory Factor Analysis (CFA) in AMOS and R. We employed PCA in CFA model fitting and evaluated the effects with Root Mean Square Error of Approximation (RMSEA), PCLOSE, Comparative Fit Index (CFI), Tucker-Lewis Index (TLI), Goodness of Fit Index (GFI), Adjusted GFI (AGFI), Relative Chi-Square of the discrepancy (CMIN/DF), Akaike Information Criterion (AIC), Bayesian Information Criterion (BIC) and Comparative Fit Index (CFI). It should be wealth noted that the thresholds of the aforementioned indices can be found in Table 3 to be considered as good fit, [36]. In the case of AIC and BIC values, the smaller, the better. 
Table 1 . Reliability and validity.

\begin{tabular}{ccccc}
\hline Constructs & $\begin{array}{c}\text { Composite } \\
\text { Reliability (CR) }\end{array}$ & $\begin{array}{c}\text { Average Variance } \\
\text { Extracted (AVE) }\end{array}$ & $\begin{array}{c}\text { Cronbach's } \\
\text { alpha }\end{array}$ & Validity \\
\hline Technology & 0.889 & 0.616 & 0.847 & established \\
Economy & 0.885 & 0.658 & 0.829 & established \\
Motivation & 0.896 & 0.742 & 0.835 & established \\
Government Policy & 0.853 & 0.658 & 0.758 & established \\
Youth Farming & 0.816 & 0.596 & 0.795 & established \\
\hline
\end{tabular}

Source: authors' computations.

Table 2. Descriptive statistics of the questionnaire (measurement item).

\begin{tabular}{|c|c|c|c|}
\hline Factor Variable & Mean & Std. Deviation & $\mathrm{N}$ \\
\hline \multicolumn{4}{|c|}{ Youth Farming } \\
\hline MEF1 & 3.12 & 0.934 & 310 \\
\hline MEF2 & 2.43 & 0.874 & 310 \\
\hline MEF3 & 2.84 & 1.106 & 310 \\
\hline \multicolumn{4}{|c|}{ Technology } \\
\hline $\mathrm{T} 1$ & 2.90 & 0.922 & 310 \\
\hline $\mathrm{T} 2$ & 2.28 & 0.962 & 310 \\
\hline T3 & 2.92 & 0.945 & 310 \\
\hline $\mathrm{T} 4$ & 2.62 & 1.029 & 310 \\
\hline T5 & 2.26 & 0.916 & 310 \\
\hline \multicolumn{4}{|c|}{ Economic } \\
\hline Econ 1 & 1.53 & 0.783 & 310 \\
\hline Econ 2 & 1.57 & 0.776 & 310 \\
\hline Econ3 & 1.83 & 0.794 & 310 \\
\hline Econ 4 & 1.98 & 0.901 & 310 \\
\hline \multicolumn{4}{|c|}{ Motivation } \\
\hline M1 & 1.77 & 0.822 & 310 \\
\hline M2 & 1.87 & 0.940 & 310 \\
\hline M3 & 1.80 & 0.745 & 310 \\
\hline \multicolumn{4}{|c|}{ Government Policies } \\
\hline GP1 & 1.91 & 0.847 & 310 \\
\hline GP2 & 1.90 & 0.771 & 310 \\
\hline GP3 & 2.04 & 0.895 & 310 \\
\hline
\end{tabular}

Source: author's computation.

Table 3. Factor loadings (loading $>0.2$ eigen value are in bold) ${ }^{\mathrm{a}}$.

\begin{tabular}{cccccc}
\hline \multicolumn{7}{c}{ Component } \\
\hline Factor Variable & 1 & 2 & 3 & 4 & 5 \\
\hline T3 & $\mathbf{0 . 8 1 8}$ & -0.026 & -0.016 & -0.097 & 0.120 \\
T4 & $\mathbf{0 . 8 1 4}$ & -0.058 & -0.010 & -0.046 & 0.028 \\
\hline
\end{tabular}


Continued

\begin{tabular}{cccccc}
\hline T2 & $\mathbf{0 . 8 0 6}$ & 0.037 & -0.017 & 0.099 & -0.021 \\
T1 & $\mathbf{0 . 7 6 3}$ & -0.109 & -0.043 & -0.049 & 0.103 \\
T5 & $\mathbf{0 . 7 1 7}$ & 0.172 & 0.000 & 0.023 & 0.081 \\
Econ3 & 0.003 & $\mathbf{0 . 8 3 6}$ & 0.010 & 0.010 & -0.017 \\
Econ1 & 0.046 & $\mathbf{0 . 8 2 1}$ & 0.050 & 0.064 & 0.014 \\
Econ2 & -0.120 & $\mathbf{0 . 7 9 7}$ & 0.001 & -0.022 & 0.020 \\
Econ4 & 0.086 & $\mathbf{0 . 7 8 9}$ & 0.064 & 0.157 & -0.046 \\
M2 & 0.003 & 0.028 & $\mathbf{0 . 9 0 2}$ & 0.094 & -0.003 \\
M3 & 0.000 & 0.035 & $\mathbf{0 . 8 4 3}$ & -0.050 & -0.057 \\
M1 & -0.083 & 0.055 & $\mathbf{0 . 8 3 8}$ & 0.234 & 0.015 \\
GP2 & -0.031 & 0.093 & 0.085 & $\mathbf{0 . 8 2 2}$ & 0.052 \\
GP3 & -0.040 & 0.033 & 0.091 & $\mathbf{0 . 8 1 1}$ & 0.094 \\
GP1 & 0.015 & 0.051 & 0.052 & $\mathbf{0 . 8 0 1}$ & -0.014 \\
MEF3 & 0.093 & -0.020 & -0.037 & 0.133 & $\mathbf{0 . 8 1 0}$ \\
MEF1 & 0.125 & 0.006 & 0.008 & -0.003 & $\mathbf{0 . 7 6 2}$ \\
MEF2 & 0.025 & -0.010 & -0.017 & 0.004 & $\mathbf{0 . 7 4 3}$ \\
\hline
\end{tabular}

Extraction Method: Principal Component Analysis. Rotation Method: varimax with Kaiser Normalization. a. Bolded loadings are arranged by size. Rotation converged in 5 iterations. Source: authors' computation.

\section{Study Hypothesis Using Each Construct}

The use of technological activities enables youth farmers to analyze and store data, deploy sensors and perform other functions that enhance productivity [37].

H1. Technology implementation has a positive influence on youth farming activities.

The rate at which technology application improves production motivation motivates youth farming [9].

H2. Participants are intrinsically motivated to go into farming.

Furthermore, the economic enhancement obtained from applying technology in farming activities enables youth farming [38].

H3. Economic development obtained from the application of technology has a positive influence on youth farming.

Moreover, other external activities such as policies, religion, culture, and implementation contribute to youth farming [29].

H4. Government Policies have a positive influence on youth farming.

H5. Knowledge moderate's technology application effectively in youth farming.

The knowledge on the use and enhancement of technology in agricultural farming improves the application of technology in youth farming.

H6. The attitude of the youth positively correlates with their intrinsic motivation toward youth farming.

The youth viewing farming as high or low risk for income generation has a 
positive influence on their motivation to go into farming.

\section{Result}

The pre-data-preparation showed that the participants in this study were youth between age 17 and 35 years and are fairly educated, of which males are the majority. The adequacy of each variable to be included was assessed for its appropriateness in factor analysis using the Keiser-Meyer-Olkin test (KMO test). The observed value was 0.768 , statistically significant, considering a threshold of 0.60 stated by [39]. To successfully classify the variables into five constructs, the researchers used Cattel's scree plot and the percentage of variation criterion (PVR) described by [40]. Figure 1 below shows the scree plot having eigenvalues on the vertical ( $y$-axis) and the number of constructs extracted on the horizontal ( $x$-axis). The number of components with eigenvalues greater than 1 is selected (5 according to Figure 1). The 5 constructs extracted can explain $66.88 \%$ of the variance.

The measure internal consistency of the items was assessed Cronbach's alpha, $\mathrm{CR}$, and AVE and the outcome displayed in Table 1 above. All values reported are above the threshold, which established that the content validity and reliability of the items are satisfactory.

The factor loadings for the constructs give a statistically significant percentage of variation explained and describe that technology $(\mathrm{T})$ implementation has the greatest of variance explained, $18.37 \%$, followed by the economic development (Econ) with 16.85\%; participants motivation (M) accounted for $12.69 \%$ and government policy (GP) having 10.56. Except for $\mathrm{H} 2$ and $\mathrm{H} 3$, all other hypotheses were significant at a 95\% confidence level, as shown in Table 4 . The inferential relationship between technology implementation and youth farming was positive, meaning that the ease of applying technology in agriculture tends to boost the youth to go into farming. Again, the positive relationships indicate that if appropriate governmental policies with incentives are laid down for farmers, young educated people will move into agricultural farming. Also, the negative

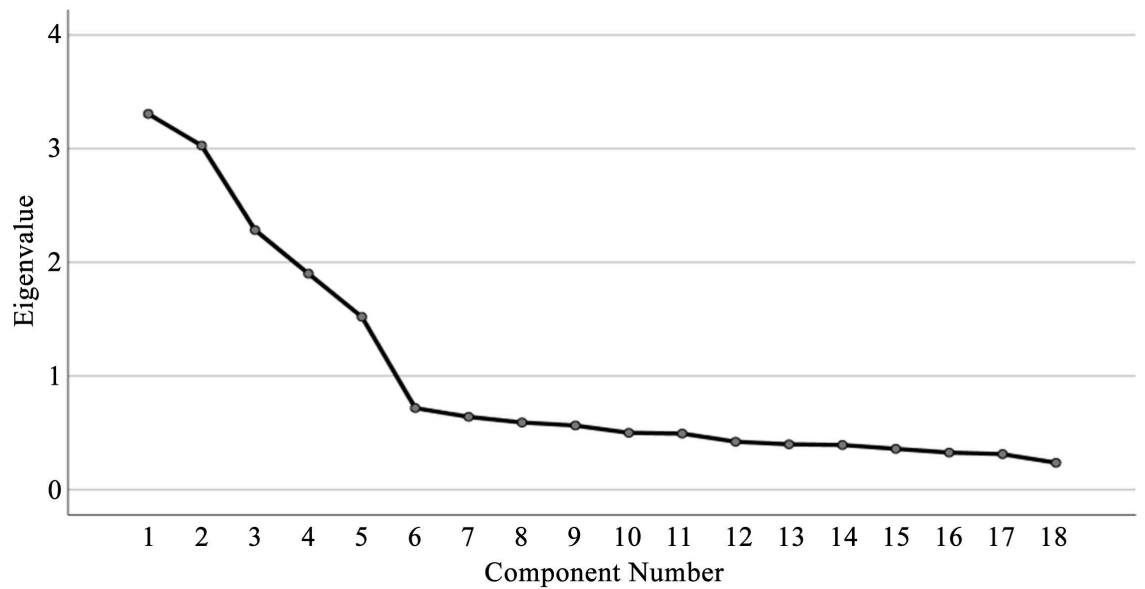

Figure 1. Scree plot of eigenvalues versus number of constructs. Source: authors' plot. 
Table 4. Path analysis of the model.

\begin{tabular}{cccccccc}
\hline & \multirow{2}{*}{ Variable } & & $\begin{array}{c}\text { Estimate } \\
(\beta)\end{array}$ & S.E. & $\begin{array}{c}\text { P-value } \\
(<0.05)\end{array}$ & Hypothesis & Result \\
\hline Youth Farming & $\leftarrow$ & Technology & 0.316 & 0.096 & 0.001 & $\mathrm{H} 1$ & Supported \\
Youth Farming & $\leftarrow$ & Economics & -0.055 & 0.095 & 0.564 & $\mathrm{H} 2$ & $\begin{array}{c}\text { Not } \\
\text { Supported }\end{array}$ \\
Youth Farming & $\leftarrow$ & Motivation & -0.076 & 0.094 & 0.418 & $\mathrm{H} 3$ & $\begin{array}{c}\text { Not } \\
\text { Supported }\end{array}$ \\
Youth Farming & $\leftarrow$ & Government Policy & 0.281 & 0.103 & 0.006 & $\mathrm{H} 4$ & $\begin{array}{c}\text { Supported } \\
\text { Technology }\end{array}$ \\
Motivation & $\leftrightarrow$ & Knowledge & -0.398 & 0.131 & 0.002 & $\mathrm{H} 5$ & Supported \\
\hline
\end{tabular}

SE: Standard Error. p-value: ${ }^{* * *}<0.0001$. Source: author’s computation.

the moderating effect of knowledge on technology implementation in farming implies that when the youth have enough knowledge on the application and performance of the technology in farming, their attitude of risk perception on farming decreases.

In Figure 2, the latent variables are marked with oval shapes, whereas the rectangles are the measurement items, and the circles labeled e1 to e23 are the unobserved variations in the model. All the variances (e1 - e23) were statistically significant at $95 \%$ confidence level during the analysis. The factor loadings are labeled on arrows from the latent variables to their respective variables, whiles the path coefficients, $\beta$ are on the paths from one latent variable to another. The model fit indices listed in Table 5 asserts that the observed research model's goodness-of-fit was satisfactory.

\section{Discussion}

The purpose of the study was to examine the factors that encourage the youth to champion agricultural farming in Ghana. Using the Exploratory Factor Analysis (EFA), the study implemented factors such as motivation, technology, economics, and external government policies that presumed to have significant effects on youth farming. Figure 2 gives the graphical representation of these relationships. The study observed that among the hypotheses which were significant to the effective assessments of the factors toward youth farming, technology accounts for a greater portion of the variance explained. Thus, signifying technology as a major determining factor that influences youth farming. We observe that technology has a positive significant relationship with youth farming, which means that technology has a direct influence on youth going into farming which toes the line of initial expectation. Researchers such as Bacco et al., [37] and Yu et al., [41] also confirmed technology's influence on youth and farming.

Also, there was a statistically significant association between government policies and youth farming ( $\mathrm{p}$-value $<0.05)$. As presented in Figure 2; government policies equally have a direct influence on youth opting to farm. Tanko, (2020) 


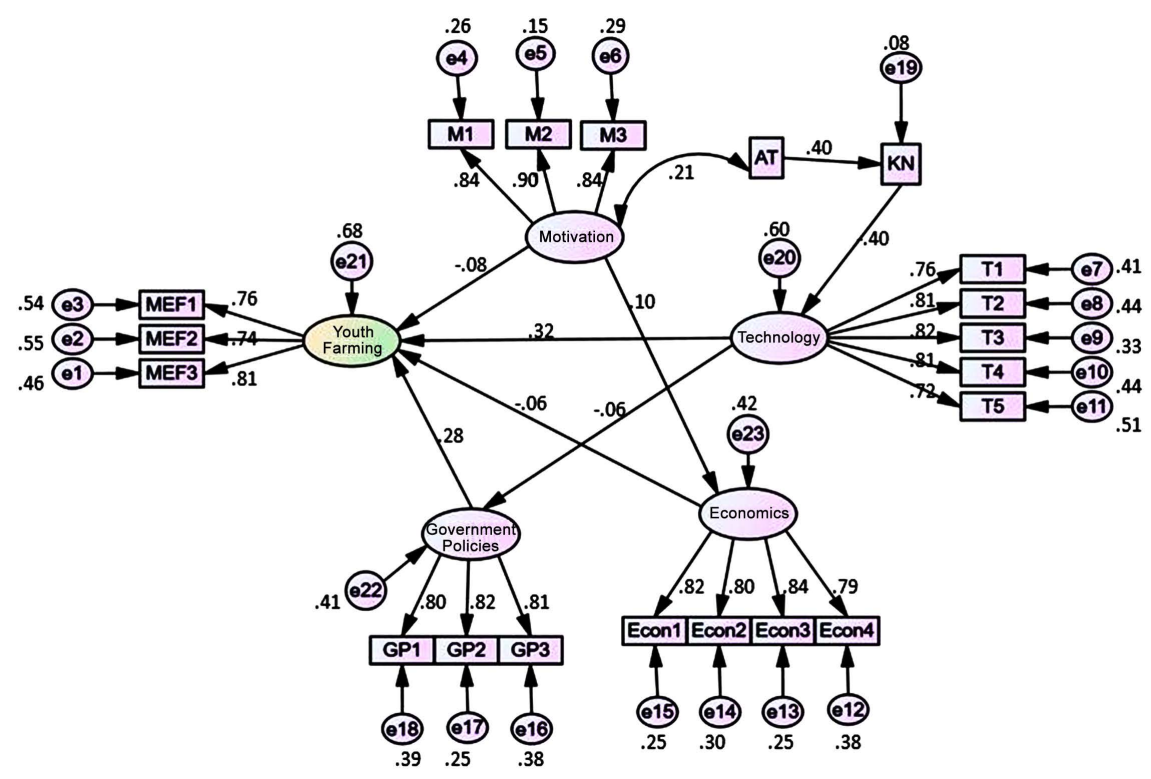

Figure 2. The structural equation model of the study.

Table 5. Model fit summary.

\begin{tabular}{ccc}
\hline Model Fit & Observed & Threshold \\
\hline RMSEA & 0.038 & $<0.08$ \\
PCLOSE & 0.972 & $>0.90$ \\
CFI & 0.963 & $>0.90$ \\
TLI & 0.957 & $>0.90$ \\
GFI & 0.933 & $>0.90$ \\
AGFI & 0.912 & $>0.90$ \\
CMIN/DF & 1.447 & $<3.0$ \\
AIC & 331.498 & Small enough \\
BIC & 518.326 & Small enough \\
\hline
\end{tabular}

confirmed that external activities such as government policies, religion, culture, and the like directly influence youth farming.

Furthermore, the relationship between motivation and youth farming was surprisingly not significant, in statistical terms. The authors discovered that the indicators for motivation were basically concerned about intrinsic motivation (where the youth have inner desire and passion to go into farming), other than the general motivation which would have given an unswerving influence on the youth farm, as was expected by the authors (see H2). It should be worth noticing that some indicators of government policy (GP) account for extrinsic kind of motivation which talks about incentive packages to entice the youth to engage in agricultural farming. Supported by Damba et al., [9] motivation influence people's behavior, especially the youth, to go into the variable providing the source of motivation. 
The result denotes that the relationship between economic and youth farming is not statistically significant, yet the interaction of economic factors with motivation increases the absolute total effect of motivation on youth farming. This means that when the youth is intrinsically motivated, their economic status will boost their interest in farming and researchers such as Saiz-rubio, [38] confirmed economic progress inspires the youth to practice agriculture. The youth are expected to be more inclined hence more likely when there is an ideal financial situation.

In addition, other variables such as attitude and knowledge though have no direct influence on youth farming; they moderate significantly on technology application in farming to drive the youth to have interest in agricultural farming.

Finally, besides the previously discussed factors, other indicators such as the number of family members engaged in farming (MEF1), predominant occupation of the locals (MEF2) [42], the level of education of the youth (MEF3) [43], and the availability of white-collar job or unemployment rate, among others have a great influence on the youth's involvement in farming.

\section{Conclusions}

This contemporary study analyses four empirical factors such as technology, motivation, economic and government policies impact on youth farming. Literature divulges that it is technology application in agriculture that influences the youth to farm. Still, other factors such as motivation, economic and governmental policies equally have encouraged the youth. The application and integration of these factors have been extensively accepted as the key elements that inspired youth to go into farming efficiently and effectively. The main result of the analyses shows their integration roles cannot be underestimated.

Technology was identified as a universal modern approach for the current generation of youth, who can use technology to accomplish a greater solution to humanity's food insecurity, especially on the African continent. The link between technology and youth farming was statistically significant, implying that the outcome in the sample can also be found in the general populace. Furthermore, the study observed that motivation guides the cognitive behavior of the youth towards farming and maintains them by establishing the driving force associated with the benefit of being a young farmer in the region. The analysis further denotes that motivation can also indirectly affect youth farming via economic factors allied with the youth.

Also, economic factor (material prosperity, transfer of goods and services, consumption and the like) was identified to have an optimal determinant on youth farming acceptance, although the data in this study proves otherwise at the $95 \%$ confidence level. Government Policies such as policy for better remuneration, a policy of stability of farming employment and retirement benefits, government subsidies on agricultural tools and machinery, and the like contributed to the statistically significant figures obtained during the analysis. 
The study observed that government policies serve as a direct link to influence the youth towards farming while also providing the platform for technology application to achieve the same objective. The study advances our understanding of pertinent factors that influence the youth's adoption of agriculture by establishing the direct theoretical link from these factors. The study recommends that government and stakeholders lay down efficient and effective policies to motivate the young generation of today toward youth farming for sustainability and economic development.

Finally, this present study as adding to literature has some limitations which provide the potential arena for future research. First, this research was conducted on youths in the West African region of Ghana, therefore, future research is encouraged to extend to other countries in the Sub-Saharan Africa with similar interest to boost agricultural farming among the youth. Second, the focus of this study only involved only participants at a youthful age. Extending the study to include participants of older generation may give more insight into understanding how the gap between the young and old generation keeps widening or closing in terms of the interest to go into agriculture farming is suggested for future research. Third, the present study is limited in volume and variety of data obtained from participants. A variety of factors have inherent attributes to agricultural farming, hence further study to incorporate big data and its analytics is desired. Including additional variables ad applying the right analytics will throw more light on youth involvement in agricultural farming and increase precision on information gathered.

\section{Acknowledgements}

Our gratitude goes to the anonymous reviewers.

\section{Conflicts of Interest}

The authors declare no conflicts of interest regarding the publication of this paper.

\section{References}

[1] Ayisi Nyarko, D. and Kozári, J. (2021) Information and Communication Technologies (ICTs) Usage among Agricultural Extension Officers and Its Impact on Extension Delivery in Ghana. Journal of the Saudi Society of Agricultural Sciences, 20, 164-172. https://doi.org/10.1016/j.jssas.2021.01.002

[2] Lin, T.C. and Huang, C.C. (2008) Understanding Knowledge Management System Usage Antecedents: An Integration of Social Cognitive Theory and Task Technology Fit. Information and Management, 45, 410-417. https://doi.org/10.1016/j.im.2008.06.004

[3] Verma, S.R. (2006) Impact of Agricultural Mechanization on Production, Productivity, Cropping Intensity Income Generation and Employment of Labour: Status of Farm Mechanization in India. Punjab Agricultural University, Ludhiana, 133-153.

[4] Li, W., et al. (2020) A Hybrid Modelling Approach to Understanding Adoption of Precision Agriculture Technologies in Chinese Cropping Systems. Computers and 
Electronics in Agriculture, 172, Article ID: 105305. https://doi.org/10.1016/j.compag.2020.105305

[5] Article, R. and Kapur, R. (2018) Usage of Technology in the Agricultural Sector. Acta Scientific Agriculture, 2, 78-84.

[6] Tang, Y., Dananjayan, S., Hou, C., Guo, Q., Luo, S. and He, Y. (2021) A Survey on the $5 \mathrm{G}$ Network and Its Impact on Agriculture: Challenges and Opportunities. Computers and Electronics in Agriculture, 180, Article ID: 105895. https://doi.org/10.1016/j.compag.2020.105895

[7] Verduyn, P., Schulte-Strathaus, J.C.C., Kross, E. and Hülsheger, U.R. (2020) When Do Smartphones Displace Face-to-Face Interactions and What to Do about It? Computers in Human Behavior, 114, Article ID: 106550.

https://doi.org/10.1016/j.chb.2020.106550

[8] Picatoste, J., Pérez-Ortiz, L. and Ruesga-Benito, S.M. (2018) A New Educational Pattern in Response to New Technologies and Sustainable Development. Enlightening ICT Skills for Youth Employability in the European Union. Telematics and Informatics, 35, 1031-1038. https://doi.org/10.1016/j.tele.2017.09.014

[9] Damba, O.T., et al. (2019) Effects of Technology Dissemination Approaches on Agricultural Technology Uptake and Utilization in Northern Ghana. Technology in Society, 62, Article ID: 101294. https://doi.org/10.1016/j.techsoc.2020.101294

[10] Aubert, B.A., Schroeder, A. and Grimaudo, J. (2012) IT as Enabler of Sustainable Farming: An Empirical Analysis of Farmers' Adoption Decision of Precision Agriculture Technology. Decision Support Systems, 54, 510-520.

https://doi.org/10.1016/j.dss.2012.07.002

[11] Ronaghi, M.H. and Forouharfar, A. (2020) A Contextualized Study of the Usage of the Internet of Things (IoTs) in Smart Farming in a Typical Middle Eastern Country within the Context of Unified Theory of Acceptance and Use of Technology Model (UTAUT). Technology in Society, 63, Article ID: 101415. https://doi.org/10.1016/j.techsoc.2020.101415

[12] Markovic, D., Koprivica, R., Pesovic, U. and Randic, S. (2015) Application of IoT in Monitoring and Controlling Agricultural Production. Acta Agriculturae Serbica, 20, 145-153. https://doi.org/10.5937/AASer1540145M

[13] Klerkx, L. and Rose, D. (2019) Dealing with the Game-Changing Technologies of Agriculture 4.0: How Do We Manage Diversity and Responsibility in Food System Transition Pathways? Global Food Security, 24, Article ID: 100347. https://doi.org/10.1016/j.gfs.2019.100347

[14] Pathak, A., Uddin, M.A., Jainal Abedin, M., Andersson, K., Mustafa, R. and Hossain, M.S. (2019) IoT Based Smart System to Support Agricultural Parameters: A Case Study. Procedia Computer Science, 155, 648-653. https://doi.org/10.1016/j.procs.2019.08.092

[15] Abdullahi, H.S., Mahieddine, F. and Sheriff, R.E. (2015) Technology Impact on Agricultural Productivity: A Review of Precision Agriculture Using Unmanned Aerial Vehicles. 7 th International Conference on Wireless and Satellite Systems, Bradford, 6-7 July 2015, 388-400. https://doi.org/10.1007/978-3-319-25479-1_29

[16] Berhanu, Y., Angassa, A. and Aune, J.B. (2021) A System Analysis to Assess the Effect of Low-Cost Agricultural Technologies on Productivity, Income and GHG Emissions in Mixed Farming Systems in Southern Ethiopia. Agricultural Systems, 187, Article ID: 102988. https://doi.org/10.1016/j.agsy.2020.102988

[17] Porter, M.E. and Heppelmann, J.E. (2015) How Smart, Connected Products Are Transforming Companies. Harvard Business Review. 
[18] Walter, A., Finger, R., Huber, R. and Buchmann, N. (2017) Smart Farming Is Key to Developing Sustainable Agriculture. Proceedings of the National Academy of Sciences of the United States of America, 114, 6148-6150. https://doi.org/10.1073/pnas.1707462114

[19] Kansanga, M., et al. (2019) Traditional Agriculture in Transition: Examining the Impacts of Agricultural Modernization on Smallholder Farming in Ghana under the New Green Revolution. International Journal of Sustainable Development \& World Ecology, 26, 11-24. https://doi.org/10.1080/13504509.2018.1491429

[20] Mertens, B., Sunderlin, W.D., Ndoye, O. and Lambin, E.F. (2000) Impact of Macroeconomic Change on Deforestation in South Cameroon: Integration of Household Survey and Remotely-Sensed Data. World Development, 28, 983-999. https://doi.org/10.1016/S0305-750X(00)00007-3

[21] Amankwah, E. (2011) Integration of Biogas Technology into Farming System of the Three Northern Regions of Ghana. Journal of Economics and Sustainable Development, 2, 76-86.

[22] Costello, B. and Costello, B. (2017) The Future of Us. Plur. Us, No. January.

[23] Rose, D.C. and Chilvers, J. (2018) Agriculture 4.0: Broadening Responsible Innovation in an Era of Smart Farming. Frontiers in Sustainable Food Systems, 2, 87. https://doi.org/10.3389/fsufs.2018.00087

[24] Verspagen, B. (2003) Working Paper Series. Review, Vol. 85, No. 6, 2003.

[25] Azumah, S.B., Donkoh, S.A., Awuni, J.A. and Yildiz, F. (2018) The Perceived Effectiveness of Agricultural Technology Transfer Methods: Evidence from Rice Farmers in Northern Ghana. Cogent Food \& Agriculture, 4, Article ID: 1503798. https://doi.org/10.1080/23311932.2018.1503798

[26] Weyori, A.E., Amare, M., Garming, H. and Waibel, H. (2018) Agricultural Innovation Systems and Farm Technology Adoption: Findings from a Study of the Ghanaian Plantain Sector. The Journal of Agricultural Education and Extension, 24, 65-87. https://doi.org/10.1080/1389224X.2017.1386115

[27] Simtowe, F., Marenya, P., Amondo, E., Worku, M., Rahut, D.B. and Erenstein, O. (2019) Heterogeneous Seed Access and Information Exposure: Implications for the Adoption of Drought-Tolerant Maize Varieties in Uganda. Agricultural and Food Economics, 7, Article No. 15. https://doi.org/10.1186/s40100-019-0135-7

[28] Conley, T.G., Udry, C.R., Conley, T.G. and Udry, C.R. (2000) EliScholar-A Digital Platform for Scholarly Publishing at Yale Learning about a New Technology: Pineapple in Ghana Learning about a New Technology: Pineapple in Ghana.

[29] Tanko, M. (2020) Is Farming a Belief in Northern Ghana? Exploring the Dual-System Theory for Commerce, Culture, Religion and Technology. Technology in Society, 63, Article ID: 101339. https://doi.org/10.1016/j.techsoc.2020.101339

[30] Berkhout, E., Glover, D. and Kuyvenhoven, A. (2015) On-Farm Impact of the System of Rice Intensification (SRI): Evidence and Knowledge Gaps. Agricultural Systems, 132, 157-166. https://doi.org/10.1016/j.agsy.2014.10.001

[31] Dagunga, G., Amoakowaa, A., Ehiakpor, D.S., Mabe, F.N. and Danso-Abbeam, G. (2020) Interceding Role of Village Saving Groups on the Welfare Impact of Agricultural Technology Adoption in the Upper East Region, Ghana. Scientific African, 8, e00433. https://doi.org/10.1016/j.sciaf.2020.e00433

[32] Westland, J.C. (2019) Structural Equation Models: From Paths to Networks. Springer, Berlin, 22. https://doi.org/10.1007/978-3-030-12508-0

[33] Nicolescu, L. and Nicolescu, C. (2019) Using PLS-SEM to Build an Employability 
Confidence Model for Higher Education Recipients in the Field of Business Studies. Kybernetes, 48, 1965-1988. https://doi.org/10.1108/K-04-2018-0165

[34] Comrey, A.L. and Lee, H.B. (1992) A First Course in Factor Analysis. Second Edition.

[35] Osborne, J.W. and Costello, A.B. (2004) Sample Size and Subject to Item Ratio in Principal Components Analysis. Practical Assessment, Research, and Evaluation, 9, Article 11.

[36] Hooper, D., Coughlan, J., Mullen, M.R., et al. (2008) Evaluating Model Fit: A Synthesis of the Structural Equation Modelling Literature. The Electronic Journal of Business Research Methods, 6, 53-60.

[37] Bacco, M., Barsocchi, P., Ferro, E., Gotta, A. and Ruggeri, M. (2019) The Digitisation of Agriculture: A Survey of Research Activities on Smart Farming. Array, 3-4, Article ID: 100009. https://doi.org/10.1016/j.array.2019.100009

[38] Saiz-rubio, V. (2020) From Smart Farming towards Agriculture 5.0: A Review on Crop Data Management. Agronomy, 10, 207.

https://doi.org/10.3390/agronomy10020207

[39] Dragan, D. and Topolšek, D. (2014) Introduction to Structural Equation Modeling: Review, Methodology and Practical Applications. The International Conference on Logistics \& Sustainable Transport, Celje, 19-21 June 2014.

[40] Hair Jr., J.F., et al. (2010) Multivariate Data Analysis. Pearson, London.

[41] Yu, L., Qin, H. and Xiang, P. (2020) Incentive Mechanism of Different Agricultural Models to Agricultural Technology Information Management System. Sustainable Computing: Informatics and Systems, 28, Article ID: 100423.

https://doi.org/10.1016/j.suscom.2020.100423

[42] Raabe, T. and Beelmann, A. (2011) Development of Ethnic, Racial, and National Prejudice in Childhood and Adolescence: A Multinational Meta-Analysis of Age Differences. Child Development, 82, 1715-1737.

https://doi.org/10.1111/j.1467-8624.2011.01668.x

[43] Jugert, P., Eckstein, K., Beelmann, A. and Noack, P. (2016) Parents' Influence on the Development of Their Children's Ethnic Intergroup Attitudes: A Longitudinal Analysis from Middle Childhood to Early Adolescence. European Journal of Developmental Psychology, 13, 213-230. https://doi.org/10.1080/17405629.2015.1084923 